\title{
Article
}

\section{Impact of parenting resources on breastfeeding, parenting confidence and relationships}

Crossland, Nicola, Thomson, Gillian and Moran, Victoria Louise Available at http://clok.uclan.ac.uk/30911/

Crossland, Nicola ORCID: 0000-0003-1063-8123, Thomson, Gillian ORCID: 0000-0003-3392-8182 and Moran, Victoria Louise ORCID: 0000-0003-31654448 (2020) Impact of parenting resources on breastfeeding, parenting confidence and relationships. Midwifery, 81 . ISSN 0266-6138

It is advisable to refer to the publisher's version if you intend to cite from the work. http://dx.doi.org/10.1016/j.midw.2019.102591

For more information about UCLan's research in this area go to http://www.uclan.ac.uk/researchgroups/ and search for <name of research Group>.

For information about Research generally at UCLan please go to http://www.uclan.ac.uk/research/

All outputs in CLoK are protected by Intellectual Property Rights law, including Copyright law. Copyright, IPR and Moral Rights for the works on this site are retained by the individual authors and/or other copyright owners. Terms and conditions for use of this material are defined in the policies page.

\section{CLoK}

Central Lancashire online Knowledge www.clok.uclan.ac.uk

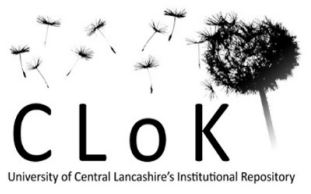




\section{Abstract}

Objective: Pregnancy and the postnatal period offers an opportunity to optimise maternal health. A UK-based charity has developed parenting resources - Baby Buddy smartphone app, Baby Express magazine, and 'From Bump to Breastfeeding' DVD - designed to complement health service care to promote maternal wellbeing, breastfeeding and positive parenting. We evaluated the embedding of these resources into maternity and early years care pathways at three sites in the north of England. Here we present results relating to the impact of the resources on breastfeeding, women's parenting confidence, and mother-infant bonding.

Design and setting: We conducted a mixed-methods study comprising a qualitative interviews and women and care provider surveys at three sites. Women's questionnaires were issued to two cohorts of postnatal women pre and post embedding of the resources. This questionnaire included validated scales (Iowa Infant Feeding Attitude Scale, Breastfeeding Self-Efficacy, Parenting Sense of Competency, Mother to Baby Bonding Scale), bespoke questions to elicit women's views of the resources and infant feeding data. A survey of professionals in the post-embedding phase explored how the resources were used in practice. Interviews with stakeholders explored views of the resources and embedding process. We conducted descriptive and inferential statistics of quantitative data, and thematic analysis of qualitative data.

Findings: There were 30 stakeholder interviews, 146 professionals completed a survey, and 161 and 192 women completed a survey before and after embedding, respectively. Receipt and use of the resources was relatively low, however, overall views of the resources were positive. There was no significant change in outcomes relating to infant feeding or parenting confidence, before and after embedding. After embedding, scores on the mother to baby bonding scale were significantly more positive when compared to pre-embedding scores.

Key conclusions: While there were issues with the receipt and use of the resources, the resources were well received by women and professionals. While the resources did not appear to have 
influenced parents' confidence and self-efficacy, there may be a positive impact on mother-infant bonding. Further research is needed to understand whether more focussed integration of the resources into care pathways over a longer term can increase user engagement, and the impact of such on key parenting outcomes.

\section{Keywords}

Breastfeeding, parenting, mother-infant relationships, maternity care, digital health, mobile phone applications

\section{Introduction}

Women's contact with health services during pregnancy and the postnatal period offer important opportunities to promote and support maternal wellbeing, breastfeeding and positive parenting practices. Breastfeeding supports the short and long-term health of both baby and mother (Victora et al. 2016). However, the decision to breastfeed is influenced by multiple complex factors at the individual, family, health system, and societal level (Dyson et al. 2009). Several studies have identified breastfeeding self-efficacy, defined as a mother's confidence in her ability to breastfeed her new infant, as an important factor in breastfeeding outcomes including duration and exclusivity (Blyth et al. 2008, Dennis 2006). Negative breastfeeding experiences and inadequate support, especially in the first weeks after birth, are significant risk factors for early termination (DiGirolamo et al. 2005).

A number of intra- and interpersonal psychological characteristics have been associated with parenting behaviours and child outcomes. One commonly investigated characteristic is parenting selfefficacy, which refers to a person's belief in their capacity to parent effectively, and is linked to satisfaction with parenting (Johnston and Mash 1989). Higher parenting self-efficacy is associated 
with positive parenting practices and positive outcomes for children (Jones and Prinz 2005) and also correlates inversely with parental stress and depression (Jones and Prinz 2005). The characteristic of mother-infant bonding refers to a mother's feelings of protectiveness and affection towards her baby, which often begin during pregnancy and increase after the baby's birth (Taylor et al. 2005). Poor bonding may be associated with maternal depression (O’Higgins et al. 2013).

During pregnancy and postnatally, women want information in relation to pregnancy, birth and caring for their baby, and value verbal and written information from health professionals (Grimes et al. 2014). Women are typically given written information during pregnancy though these materials are rarely evaluated. Warland et al (2013) used a pre-post design to investigate women's knowledge of stillbirth risk factors before and after receipt of an information leaflet; with results identifying that women who received the leaflet had higher knowledge. A recent UK study used a randomised controlled trial (RCT) to evaluate a parenting newsletter called Baby Express in a cohort of first-time mothers in a socially deprived area. The newsletter comprised 12 monthly issues which were posted to the intervention group, and self-reported parental wellbeing, parenting stress and parenting style were measured at baseline and 12 months. Overall, taking into account some differences in outcome measures at baseline, the intervention group had a lower frequency and intensity of perceived daily hassles and fewer inappropriate expectations of their infant compared to the control mothers at 12 months (Waterston et al. 2009).

Increasingly, pregnant women and new mothers are using digital technologies, including smartphone apps, as sources of information (Tripp et al. 2014). Evaluations of smartphone apps for health in the perinatal period show mixed outcomes. A recent RCT investigating the use of a smartphone app to support healthy eating and exercise during pregnancy found no additional benefits to the provision of the app alongside standard face-to-face consultations compared with standard consultations alone (Dodd et al. 2017). However, a review of the efficacy of e-technologies designed to promote, teach 
and support breastfeeding during the perinatal period found that they significantly improved initiation of exclusive breastfeeding, exclusive breastfeeding at four weeks and six months, and attitudes about breastfeeding among perinatal women (Lau et al. 2015).

Best Beginnings is a UK-based charity which creates resources to bridge maternal and child health inequalities and support parents' wellbeing through the period from pre-conception to their child's third birthday. Among the resources produced by the charity are Baby Buddy, a smartphone app, Baby Express, an age-and-stage baby magazine, and the From Bump to Breastfeeding DVD. The Baby Buddy app is free to download within the UK and contains evidence-based information throughout pregnancy and six months postnatally. It has several features to promote user engagement including a user-designed interactive avatar, gamification, goal-setting and appointment reminder features, a tailored search engine, information about local services and photo and diary features. Baby Express magazine has 12 monthly issues which contain information about infant development and parenting advice relevant to that developmental stage, designed to be visually appealing and easy to read. The magazine is an adaptation of the one evaluated in the RCT by Waterson and colleagues cited above. From Bump to Breastfeeding DVD uses real women's stories to give practical and accessible guidance for breastfeeding. These resources are designed to be easy to use and appealing to younger women. In 2014, Best Beginnings received UK Department of Health funding to embed these resources within maternity and early years' services in three UK regions, and to commission an evaluation of the impact of embedding. The aims of the evaluation were to explore how embedding was implemented and identify barriers and facilitators, to explore maternity and early years' professionals' views of the resources, and to assess the impact of embedding the resources on women's decisions, attitudes and self-efficacy in relation to breastfeeding, on women's parenting confidence, and on mother-infant relationships. The impact for younger mothers (aged under 25 years), as well as mothers of any age, was investigated since the resources were designed to appeal to young women. Here we present the findings relating to the impact of embedding the resources; the findings relating to implementation are presented elsewhere (Authors publication blinded for review). 


\section{Methods}

\section{Study design}

The evaluation used a mixed methods approach which included qualitative interviews with stakeholders; a post-embedding survey of maternity and early years professionals; and pre- and postembedding cross-sectional surveys of postnatal women. The evaluation was carried out between June 2015 and December 2016.

\section{Study context}

The study was designed to take place in the north of England with a participating site from each of the three north of England regions (North West, North East, and Yorkshire and Humber). In 2015, the study was advertised to commissioners of maternity/early years services from NHS or Local Authority (public health) organisations, who could apply to be part of the study. "Site" refers to the geographical areas receiving maternity and early years services provided by the organisations who signed up to the study. The three sites who took part were those providing requisite information (annual birth cohort size, recent breastfeeding rates, and UNICEF Baby Friendly status; see Table 1) and agreement to the terms of the study (which included buying the supply of Baby Express magazines and From Bump to Breastfeeding DVDs) within the recruitment window.

Table 1: Birth cohort and breastfeeding data for participating sites in 2015

\begin{tabular}{|l|l|l|l|}
\hline & Site One & Site Two & Site Three \\
\hline
\end{tabular}




\begin{tabular}{|c|c|c|c|}
\hline Annual births & 3000 & 4500 & 10200 \\
\hline Breastfeeding initiation $^{a}$ & $65.3 \%$ & $48 \%$ & $69 \%$ \\
\hline Breastfeeding 6-8 weeks ${ }^{\mathrm{a}}$ & $35.1 \%$ & $23.5 \%$ & $50 \%$ \\
\hline $\begin{array}{l}\text { UNICEF Baby Friendly } \\
\text { accreditation stage }\end{array}$ & $\begin{array}{l}\text { Stage } 3 \text { (Hospital Trust) } \\
\text { Stage } 1 \text { (community) }\end{array}$ & Stage 3 & Stage 3 \\
\hline
\end{tabular}

a, Breastfeeding initiation and 6-8 week data were routinely collected data supplied by the sites for the most recent quarter in 2015 prior to application to be part of the project.

A full-time Regional Facilitator from Best Beginnings worked with stakeholders at each site for the duration of the project to support the process of embedding the resources into antenatal and postnatal care pathways. An embedding plan was developed with stakeholders using an Appreciative Inquiry approach (Reed 2006) through a series of meetings and workshops. Core embedding activities ran for 6 months at each site. An overview of the embedding process is given in Table 2. Staff from relevant services were nominated to the role of "Resource Leader" if they worked with pregnant or postnatal women, and had an interest in the project. The Resource Leaders acted as champions during the embedding process, promoting the use of the resources and training healthcare and children's centre staff in their use. It was expected that these staff would then use the resources in their interactions with women. Each site was able to tailor the resources to some extent, for example by adding information about local services to the Baby Buddy app and customising the inside cover in the Baby Express magazine.

Table 2: Overview of the timeline of embedding activities

\begin{tabular}{|l|l|}
\hline Timeline & Embedding activity \\
\hline \multirow{2}{*}{ Pre-embedding } & Senior Management Team meeting: 'Making it Work' \\
\hline
\end{tabular}




\begin{tabular}{|c|c|}
\hline Month 1 & $\begin{array}{l}\text { Resource Leader workshop: 'Content and Co-creation' } \\
\text { Service user workshop: 'What do you think?' }\end{array}$ \\
\hline Month 2 & Embedding plan report produced by the Regional Facilitator \\
\hline Month 3 & Resource Leader workshop: 'The Plan In Practice' \\
\hline Month 4 & Local Launch event \\
\hline Month 6 & $\begin{array}{l}\text { Senior Management Team and Resource Leader workshop: } \\
\text { 'Progress, support and Sharing' }\end{array}$ \\
\hline $\begin{array}{l}\text { Post- } \\
\text { embedding }\end{array}$ & Progress report produced by the Regional Facilitator \\
\hline
\end{tabular}

\section{Qualitative interviews}

Interview participants were recruited via the embedding workshops and by snowball sampling to identify further stakeholders involved in the embedding work. We aimed to interview stakeholders from across different professional groups involved in the project (commissioners, midwifery, neonatal, health visiting and children's centres). Telephone interviews were conducted after the final embedding workshop had taken place. They were conducted by an experienced qualitative researcher (lead author), who was present at the workshops but had no other relationship with participants; participants were aware that the research team were not involved in developing the resources or embedding plan but had been commissioned by Best Beginnings to conduct the evaluation. Interviews were semi-structured and sought to understand participant involvement with and views of the project, perceptions of barriers and facilitators to embedding, views of the Best Beginnings resources and perceived impact, and recommendations for sustainability. The interviews lasted between 17-50 minutes, were audio-recorded and transcribed in full. 


\section{Survey of health and early years' professionals}

The questionnaire included Likert scales and free text responses. Questions aimed to assess how, and to what extent, professionals were using the resources in practice: for example, respondents were asked "If there are any specific features/information in these resources that you are more likely to use/discuss with women please can you detail these here" (free-text). The perceived impact of the resources on women was explored by asking respondents' agreement with statements such as 'The information is helping women to become more knowledgeable about their pregnancy' (Likert scale from strongly agree to strongly disagree), and respondents were also asked their views of the resources, and recommendations for improvement. Data on the respondent's age, ethnicity, gender, professional role, length of service and location were also collected. Questionnaires were issued at each site after the final embedding workshop (see Table 2). Professionals in maternity, neonatal, health visiting, and children's centres who had contact with pregnant and/or postnatal women were invited to take part. The survey was available online via the Bristol Online Survey platform and the link disseminated via email by heads of service or other senior staff with a request to participate. Paper questionnaires were also distributed by senior staff if preferred locally. Paper copies of the survey included a reply-paid envelope for direct return to the research team.

\section{Surveys of women}

The pre-embedding questionnaire included questions to explore whether women were aware of or had used the Best Beginnings resources. It included the following validated scales: (i) the Iowa Infant Feeding Attitude Scale, a 17-item scale that assesses attitudes towards breast and formula feeding and has been widely used in infant feeding studies with good levels of reliability and validity (de la Mora et al., 2006); (ii) the Parenting Sense of Competence Scale (Johnston and Mash, 1989) to explore how 
competent, confident and positive the respondent feels as a parent; (iii) the Mother to Infant Bonding Scale (Taylor et al., 2005) involves women rating how they feel about their infant on eight adjectives (e.g. loving, protective, dislike, resentful) using a four-point scale of 'not at all' to 'very much'; and (iv) the Breastfeeding Self-Efficacy Scale designed by Dennis and Faux (1999), a widely used measure assessing women's confidence in breastfeeding, with high levels of reliability and validity. Questions were also asked about current infant feeding status based on those used in the 2010 UK Infant Feeding Survey (McAndrew et al, 2012). In the post-embedding questionnaire, the same questions were asked together with additional questions to assess women's views and experiences of the resources. Women were asked about their awareness and use of the resources, such as whether they had heard of/received each resource, whether they had accessed/read the resource, the extent to which they had accessed the resources, such whether they had accessed four specific features within the app ('Today's information', daily notifications related to the woman's stage of pregnancy or age of baby; 'Ask me', a search function; 'What does this mean?', a glossary of clinical terms; and the videos) or how many magazine issues they had read. In both phases, the questionnaires asked for demographic information including age, ethnicity, parity, marital status, educational attainment and employment status.

At each phase (pre- and post-embedding) in each of the three sites, questionnaire packs were distributed to eligible women by maternity and early years' professionals. Distribution of preembedding questionnaire packs occurred in the period between the first Resource Leader workshop and the 'Local Launch' event (after which the resources began to be used in practice; see Table 2). Distribution of post-embedding questionnaire packs occurred after the final embedding workshop. Each pack contained the questionnaire, a participant information sheet, and a reply-paid envelope addressed to the research team. Women were eligible to participate if they had an infant aged between around six weeks to around six months, were aged over 17 years, were able to read/speak English and had no known mental health capacity issues. A minimum of 500 survey packs were distributed in each area at each phase. Due to low recruitment, women who took part at the post-embedding phase were 
offered a $£ 5$ shopping voucher in appreciation for their time. Online versions of each survey were also created to maximise recruitment responses using the Bristol Online Survey platform. Links to the online survey, and participant information, were distributed via social media (e.g. local group Facebook pages, a local authority Twitter feed).

\section{Data analysis}

All qualitative data was uploaded to MaxQDA10 to support data analysis (interview transcripts and qualitative data from free-text survey responses). A thematic analysis was conducted based on Braun \& Clarke's (2006) approach. Transcripts were read repeatedly. Codes and themes were developed based on the research questions and refined inductively. Analysis was conducted by the first author and final themes agreed by discussion amongst all authors.

Quantitative data were entered into SPSS v22. Descriptive analyses were undertaken for demographic categories, and for responses indicating awareness, engagement with, use of, and views of the resources. Independent samples t-tests were performed on the continuous variables (e.g. validated scales, age of infant). Chi-square tests for association between dependent and independent variables were used for other nominal/categorical variables. Due to a number of missing scores on individual items in the validated scales two linear regression models were fitted based on the set of respondents with complete records for the particular scale (one regression model for each of the two main groups - pre and post embedding). The values used for the calculation of the scales were the given answers (when available) and the predicted values from the regression models where the answer was missing. The imputation of the missing values was carried out using MICE (Multiple Imputation Chain Equations) version 2.25 for R 3.1.1 for Windows. Since the resources were designed to be appealing to younger women, additional independent samples t-tests to compare pre and post embedding scores for the subgroup of women aged under 25 years were undertaken for all the validated scales to investigate outcomes for this population. 
Also, for all the validated scales, independent samples t-tests were carried out comparing the subgroups of post-embedding women who indicated they had used/read the app or magazine with those who had not (subgroup analyses were not carried out for the DVD).

\section{Ethics}

The East Midlands-Nottingham 2 NRES Committee, and the Science, Technology, Engineering, Medicine and Health (STEMH) ethics sub-committee at the authors' institution (project no. 358), gave ethical approval for the study, and governance approval was granted by all relevant NHS trusts at each of the three sites. Participant information sheets addressed all key ethical issues including the aim and purpose of the study, voluntary nature of participation, anonymity, confidentiality and withdrawal. The women's participant information sheets also directed women to seek help from a healthcare professional if any of the questions provoked distress, and gave details of the local Patient Advice and Liaison Service for further support and advice if necessary. The Bristol Online survey tool, a secure online platform was used for the online surveys, with all data transferred to password protected computer files. Consent to participate in the surveys (paper and online) was implied by completion of the questionnaire. Stakeholders who took part in an telephone interview gave consent verbally.

\section{Findings}

First we present data on study participants. We then present a synthesis of the quantitative and qualitative findings relating to receipt and use of the resources, and impact of the resources on women's decisions, attitudes and self-efficacy in relation to breastfeeding, on women's parenting confidence, and on mother-infant relationships. In this paper, we present two of the themes found in 
the qualitative analysis - "promotion and distribution of, and engagement with, the resources" and "perceptions of the resources". An overview of the quantitative findings is given in Table 6. Where we report the percentage responses to survey questions in the text, these are presented as a proportion of those responding to the question.

\section{Participants}

A total of 30 interviews were undertaken with stakeholders: 10 from site one, 9 from site two and 11 from site three. Participants came from a range of professional groups and all were Resource Leaders apart from the commissioners (see Table 3). Where quotes are given, participants have been identified by a number and their site, but the participant's professional group is not reported to preserve anonymity.

Table 3: Numbers and types of professionals interviewed

\begin{tabular}{|l|l|l|l|}
\hline & Site One & Site Two & Site Three \\
\hline Midwifery & 2 & 2 & 2 \\
\hline Health visiting & 2 & 2 & 4 \\
\hline Family Nurse Partnership & 1 & 1 & 0 \\
\hline Breastfeeding peer support & 0 & 0 & 1 \\
\hline Children's centre staff & 5 & 3 & 4 \\
\hline Commissioning & & 1 & 1 \\
\hline Total & $0^{\mathrm{a}}$ & & 11 \\
\hline
\end{tabular}


${ }^{\mathrm{a}} \mathrm{A}$ new commissioner came into post in Site One during the latter stages of the project and so a decision was made not to request an interview since this individual had had limited experience of the project.

A total of 146 professionals completed a survey (see Table 4 for characteristics of respondents). Most respondents were midwifery, health visiting or children's centres staff.

Table 4: Demographic characteristics of professionals' survey respondents $(n=146)$

\begin{tabular}{|c|c|}
\hline & $\mathrm{N}(\%)$ \\
\hline \multicolumn{2}{|l|}{ Age (years) } \\
\hline Under 25 & $1(0.7 \%)$ \\
\hline $25-29$ & $11(7.5 \%)$ \\
\hline $30-34$ & $23(15.8 \%)$ \\
\hline $35-39$ & $16(11.0 \%)$ \\
\hline $40-44$ & $20(13.7 \%)$ \\
\hline $45-49$ & $21(14.4 \%)$ \\
\hline $50-54$ & $25(17.1 \%)$ \\
\hline $55-59$ & $9(6.2 \%)$ \\
\hline $60-64$ & $4(2.7 \%)$ \\
\hline Missing data & $16(11.0 \%)$ \\
\hline \multicolumn{2}{|l|}{ Gender } \\
\hline Female & $137(93.8 \%)$ \\
\hline
\end{tabular}




\begin{tabular}{|l|l|}
\hline Male & $1(0.7 \%)$ \\
Missing data & $8(5.5 \%)$ \\
\hline Ethnic background & \\
\hline White British & $135(92.5 \%)$ \\
White Irish & $1(2.1 \%)$ \\
Black Caribbean & $1(0.7 \%)$ \\
Other Black/Black British & $1(0.7 \%)$ \\
Other ethnic group & $5(3.4 \%)$ \\
Missing data & $49(33.6 \%)$ \\
\hline Professional group & $5(3.4 \%)$ \\
\hline Midwifery & \\
\hline Nealth visiting & \\
\hline
\end{tabular}

One hundred and sixty-one women in the pre-embedding phase and 192 in the post-embedding phase completed the questionnaire (see Table 5 for socio-demographic characteristics). Respondents were 
mostly first-time mothers, aged over 30, White British, married, in a civil partnership or cohabiting, were in paid employment and had stayed in full-time education over the age of 19 . There was no significant difference between the pre- and post-embedding samples in the mother's age, ethnicity, parity, age at which she left full-time education, or infant's age.

Table 5: Demographic characteristics of women's survey respondents

\begin{tabular}{|c|c|c|}
\hline & Pre-embedding $(\mathrm{n}=161)$ & Post-embedding $(\mathrm{n}=192)$ \\
\hline \multicolumn{3}{|l|}{ Age (years) } \\
\hline Under 20 & $4(2.5 \%)$ & $4(2.1 \%)$ \\
\hline $20-24$ & $19(11.8 \%)$ & $20(10.4 \%)$ \\
\hline $25-29$ & $39(24.2 \%)$ & $49(25.5 \%)$ \\
\hline $30-34$ & $63(39.1 \%)$ & $72(37.5 \%)$ \\
\hline $35-39$ & $30(18.6 \%)$ & $43(22.4 \%)$ \\
\hline 40 or over & $4(2.5 \%)$ & $2(1.0 \%)$ \\
\hline Missing data & $2(1.2 \%)$ & $2(1.0 \%)$ \\
\hline \multicolumn{3}{|l|}{ Ethnic background } \\
\hline White British & $149(92.5 \%)$ & $170(88.5 \%)$ \\
\hline White Irish & $1(0.6 \%)$ & $2(1.0 \%)$ \\
\hline Other white & $6(3.7 \%)$ & $0(0 \%)$ \\
\hline Indian & $1(0.6 \%)$ & $1(0.5 \%)$ \\
\hline Pakistani & $0(0 \%)$ & $2(1.0 \%)$ \\
\hline Black African & $0(0(0 \%)$ & $1(0.5 \%)$ \\
\hline Arab & $0(0 \%)$ & $1(0.5 \%)$ \\
\hline Other & $0(0 \%)$ & $12(6.3 \%)$ \\
\hline Missing data & $4(2.5 \%)$ & $3(1.6 \%)$ \\
\hline Marital status & & \\
\hline
\end{tabular}




\begin{tabular}{|c|c|c|}
\hline Married or in a civil partnership & $83(51.6 \%)$ & $106(55.2 \%)$ \\
\hline Living together & $54(33.5 \%)$ & $56(29.2 \%)$ \\
\hline Single & $16(9.9 \%)$ & $26(13.5 \%)$ \\
\hline Widowed, divorced or separated & $1(0.6 \%)$ & $0(0 \%)$ \\
\hline Missing data & $7(4.3 \%)$ & $4(2.1 \%)$ \\
\hline \multicolumn{3}{|l|}{ Age (years) completed full-time education } \\
\hline 16 or under & $14(8.7 \%)$ & $33(17.2 \%)$ \\
\hline 17 & $9(5.6 \%)$ & $10(5.2 \%)$ \\
\hline 18 & $24(14.9 \%)$ & $22(11.5 \%)$ \\
\hline 19 or over & $105(65.2 \%)$ & $119(62.0 \%)$ \\
\hline Missing data & $9(5.6 \%)$ & $8(4.2 \%)$ \\
\hline \multicolumn{3}{|l|}{ Occupation } \\
\hline Studying/training at school, college or university & $6(3.7 \%)$ & $7(3.6 \%)$ \\
\hline Working in an unpaid job & $0(0 \%)$ & $2(1.0 \%)$ \\
\hline Looking after my family & $28(17.4 \%)$ & $37(19.3 \%)$ \\
\hline Not in education, employment or training & $0(0 \%)$ & $1(0.5 \%)$ \\
\hline (because of illness or disability) & & \\
\hline Not in education, employment or training (for & $3(1.9 \%)$ & $5(2.6 \%)$ \\
\hline other reasons) & & \\
\hline Working in a paid job & $121(75.2 \%)$ & $137(71.4 \%)$ \\
\hline Missing data & $3(1.9 \%)$ & $3(1.6 \%)$ \\
\hline \multicolumn{3}{|l|}{ Parity } \\
\hline First baby & $105(65.2 \%)$ & $111(57.8 \%)$ \\
\hline Second or subsequent baby & $55(34.2 \%)$ & $79(41.1 \%)$ \\
\hline Missing data & $1(0.6 \%)$ & $2(1.0 \%)$ \\
\hline \multicolumn{3}{|l|}{ Multiple birth (most recent baby) } \\
\hline Singleton & $157(97.5 \%)$ & $185(96.4 \%)$ \\
\hline
\end{tabular}




\begin{tabular}{|l|l|l|}
\hline Twin & $2(1.2 \%)$ & $3(1.6 \%)$ \\
Triplet or other multiple & $0(0 \%)$ & $1(0.5 \%)$ \\
Missing data & $2(1.2 \%)$ & $3(1.6 \%)$ \\
\hline Total number of children & & \\
\hline 1 & $102(63.4 \%)$ & $111(57.8 \%)$ \\
2 & $36(22.4 \%)$ & $52(27.1 \%)$ \\
3 & $10(6.2 \%)$ & $19(9.9 \%)$ \\
4 & $5(3.1 \%)$ & $6(3.1 \%)$ \\
5 & $2(1.2 \%)$ & $1(0.5 \%)$ \\
6 & $0(0 \%)$ & $1(0.5 \%)$ \\
Missing data & $6(3.7 \%)$ & $2(1.0 \%)$ \\
\hline -12 & $44(27.3 \%)$ & $39(20.3 \%)$ \\
\hline Age of child (weeks) & $21(13.0 \%)$ & $5(18.8 \%)$ \\
\hline $0-6$ & $5(3.1 \%)$ & $5(2.6 \%)$ \\
\hline
\end{tabular}

\section{Receipt and use of the resources}

In the post-embedding survey, 75\% of women (143/192) had heard of the Baby Buddy app, compared with $27 \%$ (43/161) in the pre-embedding survey. In the post-embedding survey, women were asked if they had accessed four specific features within the app. 'Today's information' was accessed by 57\% of respondents; 'Ask me' by $39 \%$; 'What does this mean?' by $42 \%$; and the videos were accessed by 
$39 \%$ of respondents. However, between $40-57 \%$ of these respondents omitted to answer subsequent questions about their frequency of accessing each feature. Of those who did answer, the most common response was 2-5 times. Several respondents to the professionals' survey mentioned the videos feature as particularly beneficial, with one respondent expressing the view: 'Think the videos re feeding especially helpful when at home particularly in the night if struggling' (Professionals survey 19, Site One).

In the post-embedding survey, 54\% of women reported receiving a copy of the Baby Express magazine. This was less than anticipated and was likely due to difficulties with delivery of the magazine. While details of these challenges are discussed in-depth elsewhere (blinded for review), at all three sites copies were delivered by professionals at standard contacts. This necessitated women receiving batches of the magazines rather than a monthly issue, and also relied on women collecting some issues (i.e. at local children's centres). The median number of copies received overall was three. Most women who had received a copy of the magazine engaged with it to some extent, with only $12.6 \%$ of respondents stating they had not read any of the information in any issue of the magazine.

In the post-embedding survey, 61 of 192 women had received a copy of From Bump to Breastfeeding DVD.

In the following sections we report findings relating to breastfeeding outcomes (including attitudes to infant feeding and breastfeeding self-efficacy), parenting confidence, and mother-infant relationships, contextualised by related qualitative findings.

\section{Infant feeding}




\section{Breastfeeding rates}

In the surveys, women were asked how they had fed their baby in the last seven days. In both surveys, the percentage of women breastfeeding was higher than would have been expected based on the routine 6-8 week breastfeeding data for each site. While point percentage increases in women providing their infants with 'any' breastmilk were identified at site one (pre $=77.8 \%$ v. post $=84.5 \%$ ) and site two (pre $=34.6 \% \mathrm{v}$. post $=41.3 \%$ ), there was no significant association between infant feeding method in the pre- versus post-embedding cohorts for the total population $\left(\chi^{2}(1, \mathrm{~N}=346)=0.02, \mathrm{p}=0.89\right)$ or mothers at site one $\left(\chi^{2}(1, \mathrm{~N}=94)=0.67, \mathrm{p}=0.41\right)$, site two $\left(\chi^{2}(1, \mathrm{~N}=132)=0.59, \mathrm{p}=0.44\right)$ or site three $\left(\chi^{2}(1, \mathrm{~N}\right.$ $=120)=1.07, \mathrm{p}=0.30$ ). There was also no significant association in infant feeding method in mothers aged under 25 years across the two cohorts $\left(\chi^{2}(1, N=46)=0.00, p=1.00\right)$. In the post-embedding cohort, there was no significant association in feeding method between women who had used the app $\left(\chi^{2}(1\right.$, $\mathrm{N}=140)=0.001, \mathrm{p}=0.97)$ or read the magazine $\left(\chi^{2}(1, \mathrm{~N}=102)=0.08, \mathrm{p}=0.77\right.$. $)$ with those who had not.

\section{Infant feeding attitudes}

When scores on the Infant Feeding Attitudes Scale were compared, there was no significant difference between the pre- and post-embedding cohorts in the total sample $(\mathrm{t}(351)=1.42, \mathrm{p}=0.16)$, or at site one $(\mathrm{t}(93)=0.91, \mathrm{p}=0.37)$, site two $(\mathrm{t}(134)=-0.35, \mathrm{p}=0.73)$, or site three $(\mathrm{t}(120)=1.87, \mathrm{p}=0.07)$. There was also no significant difference in infant feeding attitudes in women aged under 25 years between the two cohorts $(\mathrm{t}(45)=0.09, \mathrm{p}=0.92)$. Mean scores and standard deviations for the Infant Feeding Attitude Scale are shown in Table 6. No significant difference in attitudes was seen between women who had used the app $(\mathrm{t}(141)=-0.8, \mathrm{p}=0.43)$ or read the magazine $(\mathrm{t}(101)=-0.31, \mathrm{p}=0.76)$ compared with those who had not (post-embedding cohort).

Insert table 6 here 
Overall, there were only a small number of comments recorded in the surveys concerning the impact of the resources on infant feeding attitudes. However, a few women described how the Baby Buddy app provided helpful information in relation to breastfeeding:

I found all the information informative and helpful regarding latching, how often to feed my baby and where to seek support. I felt I didn't need to watch the videos but it is good they are there as some people would prefer to watch them then read. (Women's post-embedding survey 42, Site Two)

In addition to helping inform women about breastfeeding, some survey respondents who were bottlefeeding noted that they valued being able to use the resources for information:

I planned on breastfeeding, but myself and child just couldn't get the hang of it, and I was worried my child wasn't getting enough milk. I decided to bottle-feed but I didn't know anything about it, so I used the app to get the info. (Women's post-embedding survey 154, Site Three).

\section{Breastfeeding self-efficacy}

Independent t-tests revealed no significant difference in breastfeeding self-efficacy scores pre and post scores for the total sample $(\mathrm{t}(351)=-0.25, \mathrm{p}=0.80)$, or between the cohorts at site one $(\mathrm{t}(93)=0.12$, $\mathrm{p}=0.91)$, site two $(\mathrm{t}(134)=-0.94, \mathrm{p}=0.35)$ or site three $(\mathrm{t}(120)=0.16, \mathrm{p}=0.88)$. Mean scores and standard deviations for the breastfeeding self-efficacy scale are shown in Table 6. When comparing between the cohorts for the mothers aged 25 years and under, younger mothers had higher self-efficacy scores in the 
post cohort compared to the pre cohort; however, this difference was not significant $(t(45)=-1.17$, $\mathrm{p}=0.25$ ). No significant difference was seen between post-embedding cohort women who had used the app $(\mathrm{t}(141)=-0.38, \mathrm{p}=0.7)$ or read the magazine $(\mathrm{t}(101)=0.6, \mathrm{p}=0.54)$ compared with those who had not.

Despite the lack of statistically significant findings, qualitative data suggested that breastfeeding information in the Baby Buddy app helped to reassure women that their baby's behaviours were normal and gave them information that helped when they were uncertain whether breastfeeding was going well. Similarly, seeing the stories of 'real' women in the videos contained in the Baby Buddy app and the From Bump to Breastfeeding DVD helped boost women's confidence in their decision to breastfeed and to breastfeed outside the home:

Reading about breastfeeding helped me gain confidence as I didn't want to feed in public at first. (Women's post-embedding survey 53, Site Two)

\section{Parenting confidence}

Overall there was no significant difference in Parenting Sense of Competency scores between the preembedding v. post-embedding phases for the total population $(\mathrm{t}(351)=1.40, \mathrm{p}=0.16)$ or at site two $(\mathrm{t}(134)=0.56, \mathrm{p}=0.58)$ or site three $(\mathrm{t}(120)=0.02, \mathrm{p}=0.98)$. However, at site one, mothers in the preembedding cohort had significantly higher scores compared to those in the post-embedding cohort $(\mathrm{t}(57.07)=2.09, \mathrm{p}=0.04)$ There was also no significant relationship between scores in mothers under 25 years across the two cohorts $(\mathrm{t}(45)=0.63, \mathrm{p}=0.53)$. Means and standard deviations are shown Table 6 . No significant difference was seen between post-embedding cohort women who had used the app $(\mathrm{t}(141)=1.16, \mathrm{p}=0.25)$ or read the magazine $(\mathrm{t}(101)=0.31, \mathrm{p}=0.76)$ compared with those who had not. 
However, qualitative data suggested that the resources offered women reassurance. One stakeholder related how she recommended the Baby Buddy app to women coping with high levels of anxiety as a means to help 'normalise' aspects of their experience:

We have got some mums who have got hyper-anxiety and who we have particularly encouraged to use the app to sort of normalise their anxieties (Stakeholder interview participant 16, Site Three).

The regular information on their baby's development was mentioned by several respondents as another particularly appreciated feature of the Baby Buddy app. Women described feeling engaged by the daily information and felt it prompted 'ideas' and gave reassurance:

I love checking the app daily to see what hints/tips are there for today. It has given me ideas about my baby's development and reassured me on numerous occasions. (Women's postembedding survey 156 , Site Thee)

One woman noted that she had been unable to put the app on her own phone and so her partner had downloaded the app to his phone; this in turn helped her partner's confidence in supporting her:

It has helped my husband gain an understanding and enabled him to have the confidence in helping me to solve problems. We have found the "Ask me" section very useful. Videos also very good. (Women's post-embedding survey 157 , Site Three) 
The age-and-stage format of the Baby Express magazine, and its emphasis on caregiver-baby interaction also helped some parents tailor their interactions to their baby's age:

How baby is developing at each month and ideas of how to interact with baby at the stage they are at. Brilliant magazines! (Women's post-embedding survey 3, Site One)

\section{Mother-infant bonding}

Overall, women in the post-embedding sample had significant higher, and more positive scores on the Mother-Baby Bonding Scale when compared to scores from the pre-embedding sample $(\mathrm{t}(230.28)=4.43, \mathrm{p}<0.01)$. Significant improvements were also shown for mothers in sites two $(\mathrm{t}(134)=3.30, \mathrm{p}<0.01)$ and three $(\mathrm{t}(119.89)=3.78, \mathrm{p}<0.01)$, but not at site one $(\mathrm{t}(93)=1.34, \mathrm{p}=0.18)$. While scores in mothers under 25 years were improved in the post-embedding phase, this did not reach significance $(\mathrm{t}(45)=1.87, \mathrm{p}=0.07)$. No significant difference in relationship scores was seen between post-embedding cohort women who had used the app $(\mathrm{t}(141)=-1.12, \mathrm{p}=0.27)$ or read the magazine $(\mathrm{t}(101)=0.13, \mathrm{p}=0.9)$ compared with those who had not. Mean scores and standard deviations are shown in Table 6.

Qualitative data from health care providers suggested how the resources may have served to promote positive maternal feelings. The professional quoted below offered the view that the resources gave professionals a starting point to stimulate discussion with women about bonding and the mother-baby relationship:

The messages in all three resources enable very meaningful conversations too which support with bonding and attachment. (Professionals survey 26, Site One) 
One stakeholder reported how the daily messages from the Baby Buddy app had helped one of her clients develop more positive feelings towards her pregnancy, and appeared to have had a beneficial effect on her wellbeing:

It basically is a client who I knew previously, and she has had maternal mood concerns in the past which had affected how she interacted with her baby at times, and she hadn't really before shown interest in the pregnancy. I talked about the App and she had actually gone on it and she had got a push notification which had said, it was something innocuous - I know what it was it was about the baby's growing nails, and it wasn't something that I would ever have thought of discussing with a mum-to-be. This had really caught her imagination so it was the right thing at the right time. She was much more engaged with the bump, she was touching her bump, she was talking about it. I just felt there was a whole attachment building already which could absolutely only be a positive thing for her but also for the baby, her mood had lightened which altogether was wonderful. (Stakeholder interview participant 27, Site Three)

Similarly, professionals considered the magazines to be particularly useful in supporting relationshipbuilding activities, due to both their content on child development and emphasis on responsive caregiving, illustrated by a quote from this stakeholder:

The magazines have been, it's just nice how they do things from that, sensitive care giving, and I think that message is really important because they do reiterate those sort of key things quite regularly which is great really. (Stakeholder interview participant 22, Site One) 


\section{Discussion}

The evaluation of the embedding of three Best Beginnings resources revealed no impact on the numbers of babies being provided with any breastmilk and no significant differences in women's infant feeding attitudes, breastfeeding self-efficacy or parenting confidence. However, qualitative data suggested that the resources had helped to reassure women about their baby's breastfeeding behaviours and gave them information about breastfeeding which boosted their confidence and reinforced their decision to breastfeed. Women's responses also emphasised the 'tips' and ideas for interaction which promoted confidence and reassurance. Some improvement was seen in relation to mother-infant bonding, with women significantly more positive in the post-embedding cohort compared to the pre-embedding cohort. A key point mentioned by many professionals was that the focus on relationships, child development, and parent-child interaction within the resources gave them a valuable starting point for conversations with parents.

Strengths of the study were the use of validated scales which have been used extensively in previous perinatal research (de la Mora et al., 2006, Johnston and Mash, 1989, Taylor et al., 2005, Dennis and Faux 1999. However, there were a number of limitations. The demographic characteristics of the samples, while not different between the pre- and post-embedding phases, show that our sample were mostly older, more educated mothers in employment, and that younger mothers, and those experiencing greater disadvantage, were underrepresented in our sample. For example, in our surveys, mothers aged under 25 years made up $14.3 \%$ of the pre and $12.5 \%$ of the post-embedding samples, while UK Office for National Statistics data set 'Live Births by Area of Usual Residence' for 2015 indicates that mothers in this age range made up $18 \%, 31 \%$ and $21 \%$ of mothers for sites One, Two, and Three respectively (Office for National Statistics 2016). The pre- and post-embedding surveys were cross-sectional surveys which limits the extent to which they can be compared. Outcomes were assessed relatively soon after the embedding of the resources, and so it is possible that a longer follow-up may have reported a greater impact. A further limitation is the low response rate to the 
women's surveys. Despite more than 500 questionnaires being distributed at each site at each phase, only between 35 and 82 responses per site were returned. This may have been due to the length of the questionnaires, the level of encouragement by health care providers at distribution stage, or that mothers have limited time when caring for a new baby. The relatively small sample size, particularly amongst mothers $<25$ years, also restricted opportunities to detect quantitative changes. Further research focussing on younger mothers, including in-depth qualitative data, is needed to gain more understanding of the usage and impact of the resources for this age group.

Studies of mHealth and eHealth interventions in the perinatal period have found mixed outcomes. A systematic review by Lau et al (2015) found internet-based and interactive computer agent interventions had a positive impact on breastfeeding attitudes, knowledge and confidence. However, a systematic review of mobile phone apps aiming to improve pregnancy outcomes through increasing healthy maternal behaviours found no significant improvements (Daly et al 2018). In our postembedding survey, comparisons of women who indicated they had used/read the app or magazine with those who had not found no significant differences on any of the outcomes. However, only 39$57 \%$ of respondents (depending on the feature) reporting accessing different features in the app, and we could not draw reliable conclusions about frequency of use. It is possible that greater use of the resources might have resulted in different outcomes. The importance of user engagement was seen in the RCT by Dodd et al (2017) of a smartphone app to support healthy eating and exercise in pregnancy: in this study, only around $30 \%$ of the intervention sample used the app and no improvements in outcomes were seen in the intervention group. As Comber et al (2013) note, 'engagement' in the context of digital interventions has been variously conceptualised, for example as behavioural engagement (time spent accessing and interacting with an app), cognitive engagement (the user's psychological interaction with the app), affective engagement (reflecting emotional investment in an app), or reflective engagement (where there is ongoing critical reflection). Our qualitative findings give some insights into how different aspects of engagement with the resources may be occurring with women and professionals. That some women described how they 'loved' 
checking the app daily for new information points to affective engagement; other women described how they engaged cognitively with the resources to learn new information, while reflective engagement is evidenced by professionals describing the resources as helping them to have 'meaningful conversations' with their clients.

In qualitative work by Goetz and colleagues (2017) participants preferred that eHealth applications complement rather than replace interactions with health professionals. A key component of the embedding model in this study was that professionals would use the app in their interactions with women, and our process evaluation findings (blinded for review) suggest this was happening to some extent; however, some staff reported difficulties in incorporating use of the app into busy appointments. Numerous studies have reported how time pressures affect breastfeeding support and information-giving in maternity care (e.g. Stapleton et al 2002; Dykes 2005; Schmied et al 2008); mHealth interventions may be no exception to this. However, positive findings from our qualitative data suggested that women and professionals believed that the resources promoted confidence and knowledge, and professionals believed the resources were useful tools to stimulate conversations with women.

In the evaluation of an earlier version of Baby Express magazine by Waterson et al (2009), the intervention group were found to have lower frequency and intensity of daily hassles and more appropriate expectations of their baby. It is not possible to draw direct comparisons between this study and our work since our intervention consisted of three resources and an embedding model developed with local stakeholders. One particularly notable difference is that in the RCT by Waterson et al, magazines were posted to women at monthly intervals, whereas in the current study, magazines were delivered to women at routine appointments and, due in part to logistical issues with distribution, only $54 \%$ of women in the post-embedding survey had received a copy. Of women who received a 
copy, most read at least some information in the magazines. It is possible that, if more women had received a copy of the magazine in our study, we would have seen more positive outcomes.

\section{Conclusions}

In our evaluation, embedding supportive parenting resources into maternity and early years' care pathways did not result in statistically significant changes in breastfeeding rates, attitudes towards breastfeeding, breastfeeding self-efficacy or parenting sense of competence, but improved scores in mother-infant bonding were seen. Overall the resources were well received by women and professionals, who believed they increased knowledge and confidence and helped support relationship building. Further research is needed to understand whether greater integration of the resources into care pathways over a longer term can increase user engagement, and whether this affects outcomes, and should include more detailed measures of different aspects of engagement.

\section{References}

Blyth, R., Creedy Debra, K., Dennis, C. L., Moyle, W., Pratt, J. \& De Vries Susan, M. 2008. Effect of Maternal Confidence on Breastfeeding Duration: An Application of Breastfeeding SelfEfficacy Theory. Birth, 29, 278-284.

Braun, V. \& Clarke, V. 2006. Using thematic analysis in psychology. Qualitative Research in Psychology, 3, 77-101.

Comber R., Thieme A., Rafiev A., Taylor N., Krämer N., Olivier P. (2013) BinCam: Designing for Engagement with Facebook for Behavior Change. In: Kotzé P., Marsden G., Lindgaard G., 
Wesson J., Winckler M. (eds) Human-Computer Interaction - INTERACT 2013. INTERACT 2013. Lecture Notes in Computer Science, vol 8118. Springer, Berlin, Heidelberg

Daly, L. M., Horey, D., Middleton, P. F., Boyle, F. M., \& Flenady, V. (2018). The Effect of Mobile App Interventions on Influencing Healthy Maternal Behavior and Improving Perinatal Health Outcomes: Systematic Review. JMIR mHealth and uHealth, 6(8), e10012. http://doi.org/10.2196/10012

De la Mora A, Russell D. W., Dungy C I., Losch, M. \& Dusdieker, L. 2006. The Iowa Infant Feeding Attitude Scale: Analysis of Reliability and Validity1. Journal of Applied Social Psychology, $29,2362-2380$.

Dennis C-L. 2006. Identifying predictors of breastfeeding self-efficacy in the immediate postpartum period. Research in Nursing \& Health, 29, 256-268.

Dennis, C. L. \& Faux, S. 1999. Development and psychometric testing of the Breastfeeding SelfEfficacy Scale. Research in Nursing \& Health, 22, 399-409.

Digirolamo, A., Thompson, N., Martorell, R., Fein, S. \& Grummer-Strawn, L. 2005. Intention or Experience? Predictors of Continued Breastfeeding. Health Education \& Behavior, 32, 208226.

Dodd J M., Louise, J., Cramp, C., Grivell R M., Moran L. J. \& Deussen A. R. 2017. Evaluation of a smartphone nutrition and physical activity application to provide lifestyle advice to pregnant women: The SNAPP randomised trial. Maternal \& Child Nutrition, 14, e12502.

Dykes, F. A critical ethnographic study of encounters between midwives and breast-feeding women in postnatal wards in England. Midwifery 21: 241 - 252

Dyson, L., Renfrew, M. J., Mcfadden, A., McCormick, F., Herbert, G. \& Thomas, J. 2009. Policy and public health recommendations to promote the initiation and duration of breast-feeding in developed country settings. Public Health Nutrition, 13, 137-144.

Goetz M, Müller M, Matthies ML, Hansen J, Doster A, Szabo A, Pauluschke-Fröhlich J, Abele H, Sohn C, Wallwiener M et al: Perceptions of Patient Engagement Applications During Pregnancy: A Qualitative Assessment of the Patient's Perspective. JMIR Mhealth Uhealth 2017, 5(5):e73. 
Grimes, H. A., Forster, D. A. \& Newton, M. S. 2014. Sources of information used by women during pregnancy to meet their information needs. Midwifery, 30, e26-e33.

Johnston, C. \& Mash, E. J. 1989. A Measure of Parenting Satisfaction and Efficacy. Journal of Clinical Child Psychology, 18, 167-175.

Jones, T. L. \& Prinz, R. J. 2005. Potential roles of parental self-efficacy in parent and child adjustment: A review. Clinical Psychology Review, 25, 341-363.

Lau, Y., Htun Tha, P., Tam Wai, S. W. \& Klainin-Yobas, P. 2015. Efficacy of e-technologies in improving breastfeeding outcomes among perinatal women: a meta-analysis. Maternal \& Child Nutrition, 12, 381-401.

Mcandrew F, T. J., Fellows L, Large A, Speed M, Renfrew Mj 2012. Infant Feeding Survey 2010. Leeds: Health and Social Care Information Centre.

Office for National Statistics 2016. Births by mothers' usual area of residence in the UK. 2015 dataset. URL https://www.ons.gov.uk/peoplepopulationandcommunity/birthsdeathsandmarriages/livebirths/ datasets/birthsbyareaofusualresidenceofmotheruk/2015 Accessed 18 September 2019

O’Higgins, M., Roberts, I. S. J., Glover, V. \& Taylor, A. 2013. Mother-child bonding at 1 year; associations with symptoms of postnatal depression and bonding in the first few weeks. Archives of Women's Mental Health, 16, 381-389.

Reed, J. 2006. Appreciative Inquiry: Research for Change, SAGE Publications.

Schmied V., Cooke M., Gutwein R., Steinlein E, Homer, C. 2008. Time to listen: Strategies to improve hospital-based postnatal care. Women and Birth, 21:99-105,

Stapleton H, Kirkham M, Thomas G: Qualitative study of evidence based leaflets in maternity care. BMJ : British Medical Journal 2002, 324(7338):639-639.

Taylor, A., Atkins, R., Kumar, R., Adams, D. \& Glover, V. 2005. A new Mother-to-Infant Bonding Scale: links with early maternal mood. Archives of Women's Mental Health, 8, 45-51.

Tripp, N., Hainey, K., Liu, A., Poulton, A., Peek, M., Kim, J. \& Nanan, R. 2014. An emerging model of maternity care: Smartphone, midwife, doctor? Women and Birth, 27, 64-67. 
Victora, C. G., Bahl, R., Barros, A. J. D., França, G. V. A., Horton, S., Krasevec, J., Murch, S., Sankar, M. J., Walker, N. \& Rollins, N. C. 2016. Breastfeeding in the 21st century: epidemiology, mechanisms, and lifelong effect. The Lancet, 387, 475-490.

Warland, J. 2013. Keeping baby SAFE in pregnancy: Evaluating the brochure. Midwifery, 29, 174179.

Waterston, T., Welsh, B., Keane, B., Cook, M., Hammal, D., Parker, L. \& Mcconachie, H. 2009. Improving Early Relationships: A Randomized, Controlled Trial of an Age-Paced Parenting Newsletter. Pediatrics, 123, 241. 
Table 6: Scores for infant feeding attitudes, breastfeeding self-efficacy parenting confidence, and mother-infant bonding scales

\begin{tabular}{|c|c|c|c|c|c|c|c|c|c|c|c|c|c|c|c|}
\hline & \multicolumn{3}{|c|}{ Total } & \multicolumn{3}{|c|}{ Site One } & \multicolumn{3}{|c|}{ Site Two } & \multicolumn{3}{|c|}{ Site Three } & \multicolumn{3}{|c|}{$\begin{array}{l}\text { Women aged <25 } \\
\text { years (all sites) }\end{array}$} \\
\hline & $\mathbf{N}$ & Mean & SD & $\mathbf{N}$ & Mean & SD & $\mathbf{N}$ & Mean & SD & $\mathbf{N}$ & Mean & SD & $\mathbf{N}$ & Mean & SD \\
\hline $\begin{array}{l}\text { IIFAS } \\
\text { Pre }\end{array}$ & 161 & 63.93 & 11.18 & 36 & 68.68 & 10.0 & 54 & 58.51 & 11.58 & 71 & 65.63 & 9.84 & 23 & 57.0 & 11.59 \\
\hline $\begin{array}{l}\text { IIFAS } \\
\text { Post }\end{array}$ & 192 & 62.25 & 10.97 & 59 & 66.75 & 9.96 & 82 & 59.17 & 10.17 & 51 & 61.98 & 11.73 & 24 & 56.70 & 10.09 \\
\hline $\begin{array}{l}\text { BSES } \\
\text { Pre }\end{array}$ & 161 & 47.27 & 11.39 & 36 & 48.88 & 10.40 & 54 & 44.21 & 12.32 & 71 & 48.77 & 10.81 & 23 & 43.90 & 13.60 \\
\hline $\begin{array}{l}\text { BSES } \\
\text { Post }\end{array}$ & 192 & 47.57 & 11.29 & 59 & 48.62 & 11.30 & 82 & 46.26 & 12.47 & 51 & 48.50 & 9.078 & 24 & 48.24 & 11.75 \\
\hline $\begin{array}{l}\text { PSoC } \\
\text { Pre }\end{array}$ & 161 & 43.49 & 10.39 & 36 & 47.13 & 11.27 & 54 & 42.27 & 10.15 & 71 & 42.59 & 9.83 & 23 & 42.16 & 9.83 \\
\hline
\end{tabular}




\begin{tabular}{|c|c|c|c|c|c|c|c|c|c|c|c|c|c|c|c|}
\hline $\begin{array}{l}\text { PSoC } \\
\text { Post }\end{array}$ & 192 & 42.04 & 9.16 & 59 & 42.64 & 8.09 & 82 & 41.29 & 9.88 & 51 & 42.55 & 9.22 & 24 & 40.22 & 11.10 \\
\hline $\begin{array}{l}\mathrm{MIBS}^{\mathrm{a}} \\
\text { Pre }\end{array}$ & 161 & 1.4 & 2.05 & 36 & 1.44 & 2.96 & 54 & 1.2 & 1.59 & \begin{tabular}{|l|}
71 \\
\end{tabular} & 1.53 & 1.48 & 23 & 1.23 & 1.62 \\
\hline $\begin{array}{l}\text { MIBS }^{a} \\
\text { Post }\end{array}$ & 192 & 0.6 & 1.06 & 59 & 0.85 & 1.35 & \begin{tabular}{|l|}
82 \\
\end{tabular} & 0.48 & 0.73 & 51 & 0.65 & 1.09 & 24 & 0.50 & 0.98 \\
\hline
\end{tabular}

IIFAS, Iowa Infant Feeding Attitudes Scale; BSES, Breastfeeding Self-Efficacy Scale; PSoC, Parenting Sense of Competency Scale; MIBS, Mother-Infant Bonding Scale.

a: Note that lower scores indicate more positive maternal feelings 